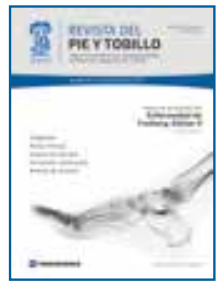

REVISTA DEL

Vol. 33. Núm. 2. Julio-Diciembre 2019

PIE Y TOBILLO

ISSN: 1697-2198 (impreso)

2173-2949 (online)

Sociedad Española de Medicina y Cirugía del Pie y Tobillo

\title{
Editorial
}

\section{Protocolos de la SEMCPT}

\section{Spanish Foot and Ankle Society protocols}

Estimados compañeros:

Os remito este editorial para anunciaros el comienzo de la publicación de los Protocolos de la SEMCPT realizados por miembros de los grupos de estudio de la sociedad. Este proyecto me fue encomendado en los comienzos de la anterior Junta Directiva, presidida entonces por nuestro actual past president: Jesus Vilá y Rico. En aquel momento, el objetivo fue analizar la situación actual de 3 problemáticas de nuestra especialidad que exigían una revisión y puesta a punto, así como crear unas guías que sirvieran de orientación en la labor diaria de todos los profesionales que engloba nuestra sociedad.

Para ello, se seleccionaron 3 problemáticas de candente actualidad:

- El estado actual de las prótesis de tobillo.

- El tratamiento de la inestabilidad de tobillo.

- El tratamiento del pie diabético.

También se seleccionaron 3 grupos de profesionales expertos en cada uno de los temas y se les solicitó que realizaran un texto que expusiera el estado actual de cada problemática, acompañado por árboles de decisión que permitieran una visualización del problema a vista de pájaro y completados por una iconografía suficiente.

El principal problema con el que nos encontramos fue que no teníamos un modelo previo en el que basarnos, lo que nos llevó a múltiples correcciones y rectificaciones tras un intenso bombardeo e intercambio de e-mails con los autores. 
Uno de los objetivos de estos protocolos era que fueran los protocolos de "todos" y para ello los publicamos durante cerca de un año en la web antes de la celebración del Congreso de Sevilla, para ello se habilitó la web y se publicaron encuestas para que todos pudieran exponer sus opiniones o correcciones a un texto definitivo, que es el que finalmente se publicó en la web.

Quiero en este punto agradecer a todos los autores y especialmente a los coordinadores de cada patología su atención y disponibilidad para todas estas tareas que pueden parecer insignificantes pero que se tradujeron en muchas horas de trabajo, conversaciones telefónicas y multitud de wasaps y mensajes de texto.

Agradecer también a la Dra. Busquets su infatigable ayuda y disposición para todas las tareas de esta coordinación.

Por último, había que darle una forma a los protocolos para que fuera posible su publicación, ya que este es el compromiso que se adquirió cuando comenzamos con el trabajo hace más de 3 años; y en esta parte ha sido decisiva la ayuda del Dr. Mario Herrera, nuestro director de la revista, para conseguir un formato publicable y despojado de todo lo accesorio o, mejor dicho, con solo lo esencial de cada escrito. De esta forma, el socio podrá elegir entre revisar el texto completo de cada uno de los protocolos, que sigue estando visible en la web de la sociedad, o el texto escrito y publicado en nuestra revista.

El primer tema en publicarse es el estudio de las prótesis de tobillo, tema que consideramos de máxima actualidad, especialmente para aquellos como yo, que en un medio con pacientes jóvenes, siempre hemos predicado a favor de la artrodesis. Creo que tras la lectura de los protocolos nos quedarán más claras las indicaciones de las prótesis, así como el modelo a elegir en cada caso o las soluciones a sus complicaciones.

Por último, creo que todo lo que publicamos en una sociedad de manera consensuada formará parte del patrimonio de la misma para siempre y esta ha sido nuestra pequeña contribución a la SEMCPT.

Esperamos que estos protocolos os sean útiles y se conviertan en una herramienta más de vuestra práctica diaria.

Un abrazo a todos,

Francisco Javier Chaqués Asensi

Coordinador de los Protocolos de la SEMCPT Vocal de Delegados Regionales y Grupos de Estudio de la SEMCPT 